Original Article

\title{
The effects of exercise using PNF in patients with a supraspinatus muscle tear
}

\author{
JWA-Jun Kim, MS, PT ${ }^{1)}$, Sang-Yeol Lee, PT, PhD²)* Kyunguin Ha, MS, PT²) \\ 1) Department of Physical Therapy, Choonhae College of Health Science, Republic of Korea \\ 2) Department of Physical Therapy, College of Science, Kyungsung University: 309 Daeyeon-dong, \\ Suyeong-ro, Nam-gu, Busan 608-736, Republic of Korea \\ 3) College of Arts School of Sports and Health, Kyungsung University, Republic of Korea
}

\begin{abstract}
Purpose] The aim of this study was to examine the effects of proprioceptive neuromuscular facilitation techniques and simple exercise on subjective pain reduction and blood flow velocity in supraspinatus tear patients and to evaluate muscle recovery. [Subjects and Methods] The 20 subjects of this study were diagnosed with supraspinatus tears by MRI. The subjects have performed PNF techniques and Simple exercise for 12 weeks. [Results] After 12 weeks of proprioceptive neuromuscular facilitation techniques and simple exercise, the blood flow velocity, Visual Analogue Scale, and disabilities of the arm, shoulder, and hand score showed statistically significant difference. Also, the difference between the proprioceptive neuromuscular facilitation techniques and simple exercise was statistically significant. [Conclusion] In conclusion, 12 weeks of proprioceptive neuromuscular facilitation treatment and simple exercise therapy had no effect on pain reduction in patients with supraspinatus tear, but in terms of functionality, the proprioceptive neuromuscular facilitation treatment was effective.

Key words: DASH, PNF, Supraspinatus tear
\end{abstract}

(This article was submitted Mar. 16, 2015, and was accepted Apr. 24, 2015)

\section{INTRODUCTION}

The shoulder joint has the largest ROM in the body. Damage often occurs to the supraspinatus muscle, which is one of the components of the shoulder, with repetitive use and small impacts ${ }^{1)}$. This is mainly because the strength of the small muscles of the shoulder joint that endure the stress from repetitive use is small ${ }^{3)}$.

The supraspinatus muscle is the muscle that forms the rotator cuff of the shoulder joints, and it is located on the top of the scapula. It plays a role in raising the arms above the head. The muscle is small, but it plays a very important role. Functional disability does not occur in accordance with the level of pain, but sometimes disability does occur in daily life when the level of pain is severe ${ }^{2,4)}$. Furthermore, $40 \%$ of adults experience rupture of the supraspinatus muscle ${ }^{5}$.

According to previous research, the main reason for damage of the supraspinatus muscle is unstable adjustment of the humeral head by the spheroidal joint or ball and socket joint ${ }^{6}$. Also, when exercise is performed that utilizes the shoulder joint, the supraspinatus, which is the small rotator muscle, has to endure it. According to previous research, 190 out of 191 rotator cuff tear patients had rupture of the

*Corresponding author. Sang-yeol Lee (E-mail: sjslh486@ hanmail.net)

C2015 The Society of Physical Therapy Science. Published by IPEC Inc. This is an open-access article distributed under the terms of the Creative Commons Attribution Non-Commercial No Derivatives (by-ncnd) License $<$ http://creativecommons.org/licenses/by-nc-nd/3.0/>. supraspinatus muscle ${ }^{7)}$.

Patients with a damaged supraspinatus muscle must go through a period of inflammation and convalescence that has no relationship with the decision regarding surgical treatment. A previous study on the treatment process for patients after a rupture in the rotator cuff reported that inflammatory response of a subacromial mucous cyst induces a patient's symptoms ${ }^{8)}$. In this kind of damage in the rotator cuff, there is a high interest in reducing pain through improvement of blood flow within the muscle. Also, with the purpose of rehabilitation, even after surgery, exercise utilizing the proprioceptive neuromuscular facilitation (PNF) method is executed within the range of no pain to normalize the supraspinatus muscle and at the same time maintain suitable stability for performance of functional activities. In other words, the PNF treatment method is an important treatment to enhance the flexibility, stability, strength, and neuromuscular control of the supraspinatus muscle ${ }^{9)}$. However, damage to the supraspinatus muscle of the shoulder joint has a high possibility of recurrence. Thus, functional disability should be prevented in the case of secondary damage. There is little information regarding PNF treatment methods in this area, and the treatment results are controversial.

Thus, the present study examined the muscle recovery level in detail by determining the speed of blood flow within the muscle and change in pain subjectively after treatment with simple exercise and PNF treatment methods in for supraspinatus muscle tear patients. 


\section{SUBJECTS AND METHODS}

This study adhered to guidelines concerning consent and ethics. It was approved by Kyungsung University's Human Research Ethics Committee. Written informed consent was obtained from all subjects after a full explanation of the experimental purpose and the protocol of the study.

The subjects of this study were patients who had visited a hospital due to shoulder joint pain and had been diagnosed with a muscle tear on MRI. They included patients who had a normal range of movement in the shoulder joint, had a post-trauma medical history, or had had shoulder joint surgery and those who had been diagnosed with two or more instances of complete rupture of the supraspinatus muscle, adhesive capsulitis, or shoulder instability. A total of 20 patients were used as subjects for this research. The patients performed rehabilitation exercise for 12 weeks, and their physical characteristics are shown in Table 1. The aim of this research was to examine in detail the types of influence on the subjective pain level and speed of blood flow in the supraspinatus muscle resulting from PNF rehabilitation exercise and simple exercise treatments performed for 12 weeks. Thus, the subjects were subjected to testing and then engaged in the rehabilitation treatment for 12 weeks. After the completion of the treatment term, the same tests as before the 12 weeks of treatment were performed using the same methods. Two rehabilitation methods, the PNF treatment method and simple exercise method, were used. The subjects warmed up 10 minutes in the same way for both methods, and the exercises were mostly stretching and were performed in the range of no pain and within the range of movement of the shoulder joint. The PNF method was used to increase the range of movement of the shoulder joint with pain in the supraspinatus muscle using relaxation techniques such as contract-relax in extension-adduct-internal rotation and flexion-abduction-external rotation. The treatment was performed within the range in which pain did not occur for 10 minutes, and the combination of isotonics facilitation method was used within the range of movement to increase muscular strength. The simple exercise was performed to improve the muscle strength and instability of the aching part through hold-relax and repetitive stretching within the range of movement of the joints in which pain did not occur. After this exercise was finished, all patients performed finishing exercises-static and dynamic stretching-for about 10 minutes. To determine the recovery level of the supraspinatus muscle, an ultrasonic Doppler blood flow meter (ES1000SP II, Hadeco, Kawasaki, Japan) was used to measure the speed of blood flow in the supraspinatus muscle. The area of the supraspinatus muscle rupture was measured a total of 12 times (every Tuesdays). The Visual Analogue Scale (VAS) was used to determine the level of pain. The first measurement was obtained before participation in the rehabilitation treatment, and a total of 12 measurements were obtained (once a week). To measure the functional aspects of daily life actions after rupture of the supraspinatus muscle, the Disabilities of the Arm, Shoulder, and Hand (DASH) questionnaire was used. The DASH questionnaire has 21 items related to everyday actions (opening a sealed container, writing letters, opening a door with a key, prepar-
Table 1. General characteristics of the subjects

\begin{tabular}{lrc}
\hline Subject & PNF $(\mathrm{n}=10)$ & \multicolumn{1}{c}{ SE $(\mathrm{n}=10)$} \\
\hline Age (years) & $47.3 \pm 3.3$ & $50.2 \pm 4.4$ \\
Weight $(\mathrm{kg})$ & $63.6 \pm 2.5$ & $59.7 \pm 4.1$ \\
Height $(\mathrm{cm})$ & $161.3 \pm 2.6$ & $163.41 \pm 1.4$ \\
\hline Mean \pm SD. & & \\
SE: simple exercise group; PNF: exercise using \\
PNF group
\end{tabular}

ing a meal, opening a door, placing an item on a shelf higher than the head, drawing up chores, taking care of a garden or gardening, laying out bedding, carrying a shopping bag or briefcase, carrying a heavy item (over $5 \mathrm{~kg}$ ), changing a light bulb, washing or drying your hair, washing your back while showering, putting on a sweater, using a knife when cooking, other activities like card games or knitting, activities consuming a lot of energy such as hammering, activities using the arms such as badminton or throwing a Frisbee, moving an item to another spot, and sexual life), items related to six symptoms (pain, pain during a certain activity, tingling, indigestion, stiffness, and sleeping disorder), and items related to 3 social functions (difficulty in social life with neighbors, limitations when working or during other activities, and decline in confidence). The questionnaire is scored from 0 points (normal) to 100 points. PASW Statistics 18.0 was used to calculate the average and standard deviation for all data in this study. The difference in DASH score, change in subjective pain, and change in speed of blood flow in the supraspinatus muscle of PNF exercise and simple exercise groups were analyzed in peated measures ANOVA. P values below 0.05 were considered to indicate statistical significance.

\section{RESULTS}

As a result of observing 20 patients who had a rupture in the supraspinatus muscle for changes in speed of blood flow in the muslce, subjective pain, and DASH csore after 12 weeks of PNF treatment and simple exercise, a significant difference was not found between the two groups, which had identical target. Change in the speed of blood flow in the supraspinatus muscle between before and after PNF treatment and simple exercise. The speed of blood flow in the supraspinatus muscle changed between before and after the PNF treatment and simple exercise for 12 weeks. The speed of blood flow in the PNF treatment group was initially $7.8 \mathrm{~m} / \mathrm{sec}(\mathrm{SD}=2.47)$. Four weeks later, it was $8.75 \mathrm{~m} / \mathrm{sec}$ $(\mathrm{SD}=3.75) ; 8$ weeks later, it was $13.22 \mathrm{~m} / \mathrm{sec}(\mathrm{SD}=7.34)$; and 12 weeks later, it was $13.41 \mathrm{~m} / \mathrm{sec}(\mathrm{SD}=6.32)$. In the simple exercise group, it was $8.14 \mathrm{~m} / \mathrm{sec}(\mathrm{SD}=2.64)$ before treatment. Four weeks later, it was $9.35 \mathrm{~m} / \mathrm{sec}(\mathrm{SD}=3.87)$; 8 weeks later, it was $9.33 \mathrm{~m} / \mathrm{sec}(\mathrm{SD}=4.21)$; and 12 weeks later, it was $8.2 \mathrm{~m} / \mathrm{sec}(\mathrm{SD}=5.11)$. As time passed, there was a statistically significant difference $(p<0.05)$. Change in subjective pain (VAS) between before and after PNF treatment and simple exercise. When looking at the change in subjective pain (VAS) between before and after PNF treatment and simple exercise, PNF the PNF treatment group 
showed a VAS score of $4.3 \pm 3.1$ before treatment and a VAS score of $3.6 \pm 2.5$ after 12 weeks. The simple exercise group showed a VAS score of $4.7 \pm 2.6$ before treatment and a VAS score of $3.7 \pm 3.7$ after 12 weeks. As a result, neither treatment method showed a statistically significant difference $(p>0.05)$. Change in DASH score between before and after PNF treatment and simple exercise. When looking at the results of the DASH questionnaires administered before and after PNF treatment and simple exercise, the PNF treatment group showed a DASH score of $23.1 \pm 10.2$ before treatment and a DASH score of $13.1 \pm 6.7$ after 12 weeks, indicating a significant decrease $(\mathrm{p}<0.05)$. The simple exercise group showed a DASH score of $21.3 \pm 11.2$ before treatment and a DASH score of $18.1 \pm 7.5$ after 12 weeks, indicating a significant difference $(\mathrm{p}<0.05)$.

\section{DISCUSSION}

In this research, 20 shoulder joint rupture patients were subjected to PNF treatment or simple exercise therapy for 12 weeks to observe their influences on the speed of blood flow in the supraspinatus muscle, change in subjective pain, and functional aspects of the shoulder joint; thus, the factors above were analyzed, and they are discussed below.

The muscles in the human shoulder joint are divided into the deltoid, subscapularis muscle, supraspinatus muscle, teres minor muscle, and teres major muscle. These muscles play a role in moving the shoulder joint in flexion, extension, abduction, adduction, internal rotation, and external rotation. It appears that rupture of the supraspinatus muscle occurs mostly from rupture of the rotator cuff of the muscles ${ }^{2)}$. The characteristics of the lesion in the supraspinatus muscle are diverse. This lesion in particular results in the most limitation and highest pain level compared with other parts of the rotator cuff ${ }^{10)}$. This is because rupture easily occurs in the joint capsule, and the ligament is also damaged due to repetitive movement in the area of the supraspinatus muscle.

The diagnosis for the supraspinatus muscle was confirmed by a radiology specialist through echography in this study. In 1984, Crass first used echography to diagnose rotator cuff rupture, and it was found that echography had a level of accuracy similar to MRI ${ }^{11)}$. According previous research, $80-90 \%$ of cases of supraspinatus muscle rupture can be determined through echography ${ }^{12)}$.

In this context, analysis of our supraspinatus muscle patients revealed that, the PNF treatment group showed an average increase of $71 \%$ in the speed of blood flow between before and after treatment. As a result, through the exercise on advance study shoulder joint pain patients, it showed that the increase in bloodstream speed of muscle, research related to pain relief, and the increase in blood flow of muscle were correspondent with partial. However, it showed a slight difference with the results of simple exercise ${ }^{13)}$. The results of the present research indicate that the PNF treatment method is more effective for muscle function recovery in patients. On the other hand, regarding the change in subjective pain, there was an average decrease of $16 \%$ between before and after the PNF treatment, whereas the average decrease was $21 \%$ between before and after simple exercise. This relaxes the contract of peripheral vascular and hypertonic of sympathetic nervous system due to hypertonic muscle due to advanced research pain. Moreover, blood circulation is accelerated for excrete colorific substances, which cuts the circulation of vicious circle ${ }^{14,15)}$ it showed different results with the research.

Blood flow increased by $71 \%$ as a result of PNF treatment, and the level of subjective pain decreased by $16 \%$. Blood flow increased by $0.7 \%$ as a result of simple exercise, and the level of subjective pain decreased by $21 \%$. A significant change was not found statistically of subjective pain decrease, increase of blood flow, and the results of advanced research.

In the DASH items concerning the functional aspects of patients with a damaged supraspinatus muscle, the total average score decreased by an average of $43 \%$ as a result of PNF treatment, but they did not show decrease rate in the requirements of using the hand such as writing, opening a door, and preparing a meal, which they felt uncomfortableness. The total average score decreased by an average of $15 \%$ as a result of simple exercise. There was no decrease in scores for putting an item on a shelf higher than the head, washing or drying your hair, and putting on a sweater. Thus, supraspinatus muscle rupture patients would not be satisfied with a treatment that results in a decrease in the total average DASH score. The total average score decreased, but both treatment methods had certain limitations that have clinical implications.

The methods used for treatment in this research show difference with the research of advanced researchers. Decrease in pain was identified in the increase of blood flow, but this has a possibility of an error during the diagnosis through echography of the damage level of the supraspinatus muscle ${ }^{16)}$. The supraspinatus muscle rupture patients did not experience pain, but there was an advanced research that patients had limitations in everyday activity like $\mathrm{DASH}^{17)}$. These were limitation of this research, and future research should use MRI and echography for diagnosis both and only utilize patients who experiencing their first case of supraspinatus muscle damage to reduce the level of errors.

\section{ACKNOWLEDGEMENT}

This research was supported by a Busan PNF Research Grant.

\section{REFERENCES}

1) Barnes DA, Tullos HS: An analysis of 100 symptomatic baseball players. Am J Sports Med, 1978, 6: 62-67. [Medline] [CrossRef]

2) Kelly BT, Williams RJ, Cordasco FA, et al.: Differential patterns of muscle activation in patients with symptomatic and asymptomatic rotator cuff tears. J Shoulder Elbow Surg, 2005, 14: 165-171. [Medline] [CrossRef]

3) Williams P, Warkick R: Gray's Anatomy, 3rd ed. Philadelphia: WB Saunders, 1980.

4) Goto M, Suzuki K, Shimada T: Relationship between lifestyle and shoulder motor function after reconstruction of rotator cuff tear. J Phys Ther Sci, 2007, 19: 243-249. [CrossRef]

5) Worland RL, Lee D, Orozco CG, et al.: Correlation of age, acromial morphology, and rotator cuff tear pathology diagnosed by ultrasound in asymptomatic patients. J South Orthop Assoc, 2003, 12: 23-26. [Medline]

6) Ferrara MS, Palutsis GR, Snouse S, et al.: A longitudinal study of injuries to athletes with disabilities. Int J Sports Med, 2000, 21: 221-224. [Medline] 
[CrossRef]

7) Fukuda H, Hamada K, Nakajima T, et al.: Pathology and pathogenesis of the intratendinous tearing of the rotator cuff viewed from en bloc histologic sections. Clin Orthop Relat Res, 1994, (304): 60-67. [Medline]

8) Smith KL, Harryman DT 2nd, Antoniou J, et al.: A prospective, multipractice study of shoulder function and health status in patients with documented rotator cuff tears. J Shoulder Elbow Surg, 2000, 9: 395-402. [Medline] [CrossRef]

9) Lee JH, Park SJ, Na SS: The effect of proprioceptive neuromuscular facilitation therapy on pain and function. J Phys Ther Sci, 2013, 25: 713-716. [Medline] [CrossRef]

10) Neer CS 2nd: Impingement lesions. Clin Orthop Relat Res, 1983, (173): 70-77. [Medline]

11) Crass JR, Craig EV, Thompson RC, et al.: Ultrasonography of the rotator cuff: surgical correlation. J Clin Ultrasound, 1984, 12: 487-491. [Medline]
[CrossRef]

12) Crass JR, Craig EV, Feinberg SB: Ultrasonography of rotator cuff tears: a review of 500 diagnostic studies. J Clin Ultrasound, 1988, 16: 313-327. [Medline] [CrossRef]

13) Lee PB, Deo JH, Sung JS, et al.: Can SUPER LIZER alleviate the local pain induced by caudal puncture? Korean Journal Pain, 2002, 15: 126-131.

14) Eiko A, Icho H: SUPER LIZER. Pain Clin, 1998, 19: 49-56.

15) Morikawa K, Kawachi A, Matsuo I, et al.: Clinical effect of SUPER LIZ ER (HA-30). Orie Med Pain Clin, 1992, 22: 37-44.

16) Miniaci A, Dowdy PA, Willits KR, et al.: Magnetic resonance imaging evaluation of the rotator cuff tendons in theasymptomatic shoulders. J Bone Joint Surg Am, 1995, 77: 10-15.

17) Jacobson JA: Musculoskeletal sonography and MR imaging. A role for both imaging methods. Radiol Clin North Am, 1999, 37: 713-735. [Medline] [CrossRef] 